\title{
Empowering strategic decision-making for wildfire management: avoiding the fear trap and creating a resilient landscape
}

Marc Castellnou ${ }^{1,2^{*}}$, Núria Prat-Guitart ${ }^{2}$, Etel Arilla', Asier Larrañaga' ${ }^{1}$ Edgar Nebot ${ }^{1}$, Xavier Castellarnau', Jordi Vendrell ${ }^{2}$, Josep Pallàs ${ }^{1}$, Joan Herrera ${ }^{1}$, Marc Monturiol ${ }^{1}$, José Cespedes ${ }^{1}$, Jordi Pagès ${ }^{1}$, Claudi Gallardo ${ }^{1}$ and Marta Miralles ${ }^{1}$

\begin{abstract}
In recent years, fire services in Mediterranean Europe have been overwhelmed by extreme wildfire behavior. As a consequence, fire management has moved to defensive strategies with a focus only on the known risks (the fear trap). In this region, wildfires can change rapidly, increasing the uncertainty and causing complex operational scenarios that impact society right from the initial hours. To address this challenge, proactive approaches are an alternative to defensive and reactive strategies.

We propose a methodology that integrates the uncertainty of decisions and the cost of each opportunity into the strategic decision-making process. The methodology takes into account values such as fire-fighting safety, organizational resilience, landscape resilience, and social values.

Details of the methods and principles used to develop and implement a creative decision-making process that empower the fireline are provided. A tool that segregates the landscape into polygons of fire potential and defines the connectivity between those polygons is used. Two examples of operational implementation of this methodology are presented (2014 Tivissa Fire and 2015 Odena Fire). These methods facilitate the analysis of possible scenarios of resolution and the costs of the opportunities that help build resilient emergency response systems and prevent their collapse. Moreover, they help explain the risk to society and involve citizens in the decision-making process. These methods are based on the experience and lessons learned by European incident commanders, managers, and researchers collected during the last decade.
\end{abstract}

Keywords: fire ecology, forest fires, resilience, risk, strategy, tactics, uncertainty

\section{Resumen}

En los últimos años, el comportamiento extremo de los incendios forestales en la Europa Mediterránea ha excedido la capacidad de extinción de los servicios de emergencias. En consecuencia, los servicios de emergencias han adoptado estrategias defensivas y han centrado su respuesta en los riesgos conocidos, lo que se conoce como trampa del miedo. En esta región europea, los incendios pueden cambiar rápidamente e impactar desde su inicio en la sociedad, aumentando así la incertidumbre y provocando escenarios operativos complejos.

(Continued on next page)

\footnotetext{
* Correspondence: incendi@yahoo.com

${ }^{1}$ Catalan Fire and Rescue Service, GRAF division, Carretera Unversitat

Autonoma s/n, 08290 Cerdanyola del Valles, Spain

${ }^{2}$ Pau Costa Foundation, Mossèn Cinto Verdaguer, 42 baixos A, 08552 Taradell, Spain
}

\section{Springer Open}

(c) The Author(s). 2019 Open Access This article is distributed under the terms of the Creative Commons Attribution 4.0 International License http://creativecommons.org/licenses/by/4.0/, which permits unrestricted use, distribution, and reproduction in any medium, provided you give appropriate credit to the original author(s) and the source, provide a link to the Creative Commons license, and indicate if changes were made. 
(Continued from previous page)

Para hacer frente a las estrategias reactivas predominantes y a sus retos, es necesario tomar iniciativas proactivas.

Proponemos en el presente artículo una metodología que integra la incertidumbre de las decisiones y el coste de cada oportunidad en el proceso de toma de decisión. La metodología tiene en cuenta valores como la seguridad de los operativos, la resiliencia de la organización, la resiliencia del paisaje y los valores de la sociedad. Los métodos descritos pretenden trasladar parte de la toma de decisiones a la línea de fuego, dotándola de poder. Presentamos también una herramienta que divide el territorio en polígonos de fuego potencial y define la conectividad entre dichos polígonos a través de dos ejemplos: el incendio de Tivissa, 2014 e incendio de Odena, 2015.

Los métodos presentados ayudan a conseguir sistemas de emergencia más resilientes y a evitar su colapso a través del análisis de posibles escenarios de resolución y la valoración del coste de las oportunidades. Además, ayudan a los ciudadanos a percibir mejor el riesgo y a involucrarse en el proceso de toma de decisiones. Estos métodos recogen las experiencias y lecciones aprendidas de gestores de emergencias e investigadores europeos en la última década.

\section{Definitions}

Fire generations: A categorization of wildfires by characteristics with regard to their social and environmental context, behavior, firefighting capacities, and impacts. This denomination is used to explain and understand wildfire activity and compare the impact of different types of fires and historical fighting approaches. Six fire generations are defined to explain the evolution of wildfires since the industrialization period.

Firefighting trap: Increasing efforts of firefighting to suppress all fires contribute to create more homogeneous and dense fuel loads. The firefighting trap (or fear trap) is the negative stress that this situation inflicts upon agencies in charge of responding to them, as they keep building resources and technologies trying to maintain efficiency and provide safety against increasingly fast, intense, and overwhelming wildfires.

Fire service culture: The set of values and priorities that define the way an organization responds to solve problems. Often this problem-solving is based on fundamental values and experience.

Maneuver: Used in the article to describe an operation or a set of fire management or suppression operations that happen during a fire event.

Opportunity cost: The benefit that is given up, when choosing one alternative over another.

Polygons of fire potential: A proposed methodology developed in this article based on fire behavior experience and pragmatic knowledge that help decisionmakers to apply fire service culture, identifying the best opportunities to meet the strategic objectives. These methods are currently being applied both in fire suppression and fire prevention and preparation.

Strategy: The chosen final scenario in which firefighters intend to solve the emergency, using the fire service culture. Strategy reduces uncertainty and provides credibility to tactical and operational decisions.

Tactical: Distribution of efforts in time and space during a wildfire event that helps to achieve the objectives and priorities defined by strategy.
Uncertainty (in fire management decision making): situation in which wildfire knowledge is too limited or unfocused to make good decisions for efficient and safe operations.

\section{Introduction \\ Mediterranean Europe context}

Over thousands of years, the landscapes of Mediterranean Europe were shaped by traditional land management practices, such as grazing, using forests as a source of many different types of resources, and contributing to the management of a scattered mosaic of agricultural lands (Chergui et al. 2018). However, in relatively recent years, rural abandonment and depopulation during the industrialization period led to a decrease in these landscape management practices, with consequent reforestation, fuel loading, and increase in fire intensity (Vega-Garcia and Chuvieco 2006; Pausas and Fernández-Muñoz 2011). All together, this has created more complex scenarios for fire management (Miralles et al. 2010; Lahaye et al. 2018). Until 20 years ago, thanks to the professionalization of fire services, the operational capacity to fight and control wildfires was successful in suppressing most wildfire emergencies. Only a few extreme fires escaped, leading to the fire suppression paradox, also known as the firefighting trap (Silva et al. 2010; Collins et al. 2013). As fuel accumulated on the landscape, fires that overwhelmed the extinction capacity got larger, faster, hotter, and spread closer to wildland-urban interfaces (WUI; Costa et al. 2011; Cardil and Molina 2015; Diakakis et al. 2016; Modugno et al. 2016).

Currently, Mediterranean Europe is highly populated with 200 million people living in France, Greece, Italy, Portugal, and Spain, and with peak densities of 750000 inhabitants $\mathrm{km}^{-2}$ during summer (San-Miguel-Ayanz et al. 2013). There are two main challenges that Europe is preparing to address in the next years. First, the risk of more devastating WUI fires, following those in Portugal in 2017 
and Greece in 2018. Second, wildfires in the Atlantic, central, and northern European regions with unprecedented fire behaviors (San-Miguel-Ayanz et al. 2018).

The fear of not being able to control devastating fires is increasing among fire services. Over time, the operational capacity of fire services has been overwhelmed by extreme fire behaviors in repeated events (MolinaTerrén et al. 2019). The response has always been an increase in efforts, causing stress and reactive approaches to the situation (CTI 2017, 2018; Palaiologou et al. 2018). Increasingly, emergency management based on large amounts of resources has been the expensive answer under the firefighting trap.

\section{Reactive strategies}

The decision-making process in Mediterranean Europe, as in other parts of the world, has evolved according to the knowledge and means available to respond to wildfire events, moving into defensive strategies (Nasiatka 2003; 2009 Victorian Bushfires Royal Commission 2010). Fire services have focused on defending against predictable, measurable, and known risks (Desmond 2011). Thus, risk management that leads decision-making focuses on protecting lives, property, and human values, following these four assumptions: (1) that safety procedures are defined based on predictable risks; (2) that focus on suppressing flames is based on estimated fire potentials to minimize the known risks (i.e., higher value and higher probability); (3) that information management focuses on increasing the information of known risks in an intelligence cell, gathering real-time information and anticipating fire behavior to maintain the initiative over the fire; and (4) that command structures focus on a tight control of large quantities of resources, prioritizing the gathering of information to make decisions.

This approach has been successful to suppress wildfires and protect citizens and firefighters in those scenarios that are certain and predictable. If the fire intensity is within the capacity of control of emergency services and the weather forecast does not show any uncertainties, the main challenges for the firefighters will be to control the perimeter of the fire (in wildfires of the first generation) or the speed of the fire head (in wildfires of the second generation). Under those circumstances, risks arise from known and routine factors-emergencies can get complex, yet they are certain and known. Risk becomes predictable, and procedures and operational techniques work. This approach has also consistently failed when facing uncertain and dynamic scenarios. If all efforts focus on the known risks instead of what is increasingly uncertain, more resources are needed to face new emerging risks. Then information is scarce, resources do not have time to efficiently respond where they are needed, and fire services collapse. Under a scenario in which uncertainty is increasing, fire services can no longer protect lives and properties.

Examples of such collapses can be found everywhere around the world. One example is the large wildfires affecting WUIs (Butler 1974; Caballero et al. 2007; BRP 2008; Calkin et al. 2014). Due to values at immediate risk (i.e., lives, properties, environment), most decisions focus on defending particular lives and assets that are at risk at that particular moment.

- Resources are allocated to face fire behaviors that overwhelm their capacity. These resources often don't have any relevant impact on the development of the emergency.

- Resources protecting assets that are at risk during the emergency are not stopping wildfire spread. The consequences of subsequent fire spread are more uncertain; as fire grows freely, it involves more and more assets requiring protection, endangering more and more assets.

- While the fire grows (e.g., in dimension, intensity, potential), the number of values at immediate risk increases faster than the capacity of gathering centralized information and responding to the fire: the information is always late.

- Tactics become reactive and defensive, with focus on responding to the most urgent risks. But these tactics do not increase the capacity of solving the emergency. Consequently, the number of threatened assets increases with time.

- The emergency absorbs a high number of resources, leaving emergency services without capacity to respond to any other emergency.

Another example is large wildfires that are highly dynamic, involving cold fronts passing through, with turbulent winds interacting with the orography and creating large convective plumes, pirocumulus, etc. (Putnam 1995; Nasiatka 2003; CTI 2017, 2018). Repeatedly, safety procedures and operations fail to respond to those unpredictable situations. Uncertain risks emerge, threatening lives and properties, and fire services lose the initiative over the emergency and become reactive.

There has been a visible shift of the fire service culture, moving from a proactive attack (initial mission and vision) to a more defensive approach based on assets at risk that need protection. This shift has been driven by an increase of uncertain situations caused by natural hazards, together with some social factors such as the changes in the relationship between the urban society and the wildlands.

Uncertainty arises as fire suppression focuses only on the known and measurable risks. The known risk 
is only one small part of the uncertainty that emerges in complex and dynamic scenarios (Fig. 1). If uncertainty is ignored in these scenarios, then unexpected risks emerge. Fire services then lose the initiative over the resolution of the emergency due to failures of the safety procedures and methodologies and the collapse of the fire suppression agencies. The results are unsafe situations for firefighters and citizens. This approach, built under pressure and fear, persists today, aggravated by climate change impacts on an increasingly urbanized society. Nevertheless, there is momentum to dedicate collective efforts to develop a creative decision-making process that considers social and natural values for current and future societies and landscapes.

\section{Objectives}

Traditionally, the culture of priorities for wildfire emergency management has been based on civil protection values at-risk: people, property, and environment. This is driving most of the emergency management systems today, but is increasing the firefighting trap that moves emergency management into a defensive-only approach.

Emergency management systems based on defensive strategies struggle with rapid changes, dynamic scenarios, and simultaneous emergencies generated by extreme wildfire behaviors (e.g., Chile in 2017, California in 2017 and 2018, and Portugal in 2017). Collaborative science is fundamental to facing those challenges; however, while

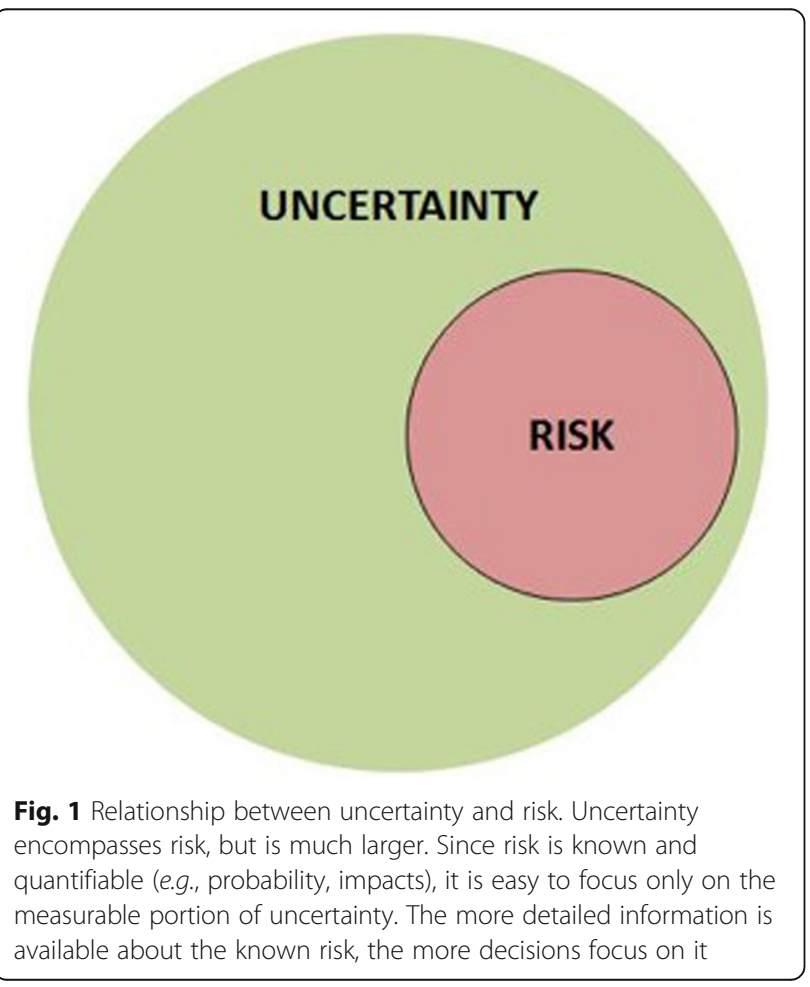

science is progressing to provide clear solutions, firefighters continue to respond to those wildfires year after year. To avoid collapse in the capacity to resolve emergencies, there is the need to develop a decision-making process that creates certainty and safety. Identifying decision traps and creative ways to prevent these traps will ensure safer working environments for firefighters during dynamic and complex situations.

In this context, detecting sources of uncertainty in fire management scenarios should unquestionably be part of the decision-making process, but bringing values such as future landscape and resilience into the decision-making equation is equally important. The objective of this paper is to describe the design and development of an experience-based methodological approach that is already operational in Mediterranean Europe. This methodology helps fire services to manage uncertainty during wildfire suppression, while creating certainty and safety, and moving away from the firefighting trap. The methods proposed do not require computational times that exceed the time available to make decisions during an emergency. They also help to maximize the positive impact of fire management for today's society and future generations. The methods are demonstrated in two real study cases with different levels of complexity.

The approach used is proven to be a useful support tool, first, for the implementation of an integrated fire management approach (Castellnou et al. 2010), and second, to enable local communities to be part of the solution by being realistic about expectations of emergency management.

\section{Challenges in the Information Age}

In response to decision-making challenges, fire services in the Mediterranean region have invested in increasing knowledge of wildfires (Costa et al. 2011; San-Miguel-Ayanz et al. 2013), focusing on integrating different values at-risk in decision-making, implementing safer procedures, and incorporating different technical solutions to address known risks (Tedim et al. 2015; Wei et al. 2018). These measures work for complicated but predictable situations, while more complex but dynamic and uncertain situations remain a challenge (Putman 1995; Nasiatka 2003; 2009 Victorian Bushfires Royal Commission 2010). For instance, fire analysis has contributed greatly to improve the firefighting system by increasing the planning capacity (Castellnou et al. 2009; Castellnou et al. 2010; Costa et al. 2011). Thus, ideally, fire analysis helps define potential at-risk values more precisely, and decisions are made with a forecast of what is going to happen next and how the decisions can affect the fire's evolution. For example, in the 2012 La Jonquera Fire, a total of 13000 ha were burned, 
and the infrastructures of three rural communities were destroyed. This was the result, in part, of the decisions made to control the fire, guarantee the suppression capacity, and safely protect a larger area of 40000 ha. Exercising an option to reduce the 13000 ha to 5000 ha would have led to uncertain and unsafe scenarios, putting more lives and assets at risk (Catalan Fire and Rescue Service 2013a).

In the Information Age, there is a tendency to collect large datasets (e.g., big data) to support decision-making (San-Miguel-Ayanz et al. 2018). But then the decision focuses on what is known rather than on what is unknown. Consequently, adding more precise information about risks does not necessarily contribute to solving the problem, but rather to adding more complexity (Weir et al. 2017). Shannon (1948) stated that, "information is the resolution of uncertainty." Information can be seen as a raster: the finer the scale, the larger the number of cells and the higher the noise. Thus, the more data and detail, the more complex are the scenarios, increasing uncertainty in decisions made (Table 1). In complex wildfire events, scenarios are highly dynamic, meaning that the amount of uncertainty can vary with time.

Distinguishing valuable information from noise is sometimes difficult (infotoxicity) and takes time, so decisions have time-lags from reality (decision-lag). In dynamic environments, reality is changing at the same time as information is being gathered from which to make a decision. Thus, the information uptake focuses on what we know best and underestimates the unknown risks and uncertainties. Infotoxicity and decision-lag contribute to making fire services more vulnerable to extreme impacts of rare and unpredictable outlier events (also known as black swans; Taleb 2007) that can cause the collapse of emergency services. The 2012 La Jonquera Fire is one example of infotoxicity. Fires in the area are often driven by strong northern winds. While analyzing fire scenarios based on northerly wind conditions was not useful for making safe and certain decisions, focusing on the new scenario after the expected wind shift at $0300 \mathrm{~h}$ (e.g., analysis of the magnitude and impact of the wind shift) was much more informative for decision-making (Catalan Fire and Rescue Service 2013a).

In this information era, the concept of uncertainty has arisen in many fields, and the type of analyses that are useful have been studied (Table 1). For instance, risk analysis is useful to address low uncertainty, such as when controlling small fires or in known wildfire flanks, or even in some parts of complex wildfires that are certain. In that case, fire operations are decided by estimating the potential of every part of the fire (a proxy of impact), and the window of opportunity for a particular operation until the next expected change of behavior (a proxy for probability of success) (Castellnou et al. 2010). As uncertainty increases, the methodological approximation should be different (Table 1; Courtney et al. 2000). In order to improve decision-making in these scenarios, simplified alternative scenarios should be identified, understanding the triggers and sources of uncertainty.

\section{Basis for an operational methodology}

Instead of adopting defensive and reactive strategies, the focus of emergency management should be on making proactive and strategic decisions (e.g., Incident Command System developed for United States, Canada, or Australia). This allows fire services to deploy safe and efficient operations during the whole emergency, thus developing organizational resilience.

Table 1 Summary table of the objectives of a decision-making process that takes into account uncertainty management. The three most relevant objectives are listed according to the suggested priority order

\begin{tabular}{|c|c|c|c|}
\hline \multicolumn{4}{|c|}{ Low $\longleftrightarrow$ Uncertainty $\longrightarrow$ High } \\
\hline Risk & Alternative future & Range of futures & True ambiguity \\
\hline & & $\uparrow$ & \\
\hline $\begin{array}{l}\text { Known probability of } \\
\text { future outputs (losses and } \\
\text { opportunities). }\end{array}$ & $\begin{array}{l}\text { A limited set of possible } \\
\text { outputs are identified, and a } \\
\text { perceived likelihood can be } \\
\text { roughly estimated. }\end{array}$ & $\begin{array}{l}\text { Sources of uncertainty } \\
\text { are identified, associated } \\
\text { with a range of illustrative } \\
\text { possible future outcomes, } \\
\text { but outputs and likelihoods } \\
\text { cannot be clearly identified. }\end{array}$ & $\begin{array}{l}\text { Uncertainty is so high that } \\
\text { it is impossible to predict a } \\
\text { range of future outcomes. }\end{array}$ \\
\hline Risk analysis. & Scenario analysis. & $\begin{array}{l}\text { Triggers (sources) of sets of } \\
\text { scenarios. }\end{array}$ & $\begin{array}{l}\text { Cannot be included in } \\
\text { analysis. }\end{array}$ \\
\hline
\end{tabular}


Instead of accumulating information about particular measurable risks, part of the uncertainty should be kept in black boxes (Table 1), and focus should be on identifying sources of uncertainty and triggers of emergency management collapse.

It must be accepted that proactive strategies bring resolution at a cost. In the 2012 La Jonquera Fire, the cost for protecting 40000 ha was to let the fire burn 13 000 ha and destroy the structures of three rural communities (Catalan Fire and Rescue Service 2013a). Thus, to minimize uncertainty and the risk of collapse, losses from known risks (opportunity costs) take place and must be accepted. In this context, the opportunity cost means to give up the most valuable choice in order to select an alternative option that preserves other essential values and ensure that resources are used efficiently (Bishop 2004). The opportunity cost is a way of being pragmatic and responsible, and of accepting that capacities to address an uncertain situation are limited. The opportunity cost would not make sense if fire services were never overwhelmed by a fire (i.e., always have enough resources available at all places, enough capacity to face all types of fire behaviors, enough information at the right pace and moment to make decisions). However, accepting uncertainty means accepting that firefighting capacities are limited and that every opportunity comes at a cost of having some loses.

A solution to the current firefighting (or fear) trap should consider structuring the culture of priorities into three different levels, starting from the fine-scale decisions up to the big picture of the incident:

\section{At maneuver level}

\section{Set of operations deployed}

These must be safe, attainable, and prioritized depending on the values at risk, following the order: people, properties, and environment. For instance, in the 2013 Vallirana Fire, instead of controlling the right flank of the wildfire, a decision was made to allocate almost $90 \%$ of the resources to protect nine houses in the area where the forest fire impacted the WUI. Later, the uncontrolled right flank affected 64 other properties (Catalan Fire and Rescue Service 2013b). If lives are not under threat, the priority at maneuver level should be to deploy those operations that impact the greater good. In the 2013 Vallirana Fire, this meant attacking the right flank of the fire in order to protect 64 properties, instead of fighting for the nine properties that were already being affected by the flames.

\section{At tactical level}

\section{The tactical level decides the allocation of efforts} (maneuvers) in time and space

Efforts should be allocated where there are opportunities to succeed with operations. At this level, the opportunities of successfully protecting values at risk and limiting the spread of the wildfire before it puts more values at risk are limited in time and space. Using one group of resources in one opportunity at one time implies not taking another action at another place. For instance, in the 2013 Vallirana Fire, all resources were allocated to defend nine houses at immediate risk, instead of distributing the resources to different sectors of the fire so that the next 64 potentially affected houses could be protected. Tactical decisions cannot be made only to protect values at risk at a certain time, but to use opportunities that help avoiding mid- and long-term risks. Thus, the order of execution of opportunities does not necessarily match the order of priorities of values at risk at a particular moment, but rather depends on the window of opportunity of each, and the potential mid-term gains and losses derived.

The culture of priorities at a tactical level should explicitly change, from defending the values at risk at a particular moment, to fostering resilience of the response system. Maintaining the initiative over the emergency is key to protecting all values.

\section{At a strategic level \\ This level chooses the final result of a fire event, encapsulating uncertainty by fixing gains and losses for each opportunity and creating a scenario of resolution where tactics and operations can succeed}

It must be accepted that uncertain environments give limited opportunities, and it's the strategy level that should provide the maximum certainty and credibility possible to the tactical and operational decision-makers. For instance, the opportunity cost of a situation by which a WUI is defended, such as in the 2013 Vallirana Fire, requires accepting uncertain damages in the WUI in order to focus on protecting other values during the total time of the emergency. In this case, this means letting the fire enter the WUI to make sure the right flank can be under control, and will not cause major damages later on. The goal of the fire service is not only to try to protect values with a known, demonstrable, and measurable risk, but also to focus on maximizing the benefits of the whole scenario. So, the culture of priorities at a strategic level is based on the common good, understood as maximizing the benefit for society as a whole, rather than only for some individuals.

\section{Proposal for improving decision-making}

The proposed methodology for the integration of the opportunity cost and scenarios of resolution at tactical and strategic decision-making levels has been developed based on European Mediterranean wildfires. These are fires that burn rapidly through the landscape, and most of the propagation happens within the first 12 to 24 hours, involving populations at risk from the first hour. Decisions have to be made under a very high level of uncertainty, 
with known values at immediate risk, and a more uncertain range of possible outcomes in the longer term.

In this Mediterranean context, the decision management framework has allowed long term strategical and tactical decisions to be carried out by responders in the first two hours of the fire. The successful implementation of the methodology proposed requires integrating principles related to firefighter safety, organizational resilience, the common good of the largest part of the population, and responsibility-sharing with society. It requires a change in the decision-making culture of the fire services, from a process based on fire suppression objectives, to a process focused on the final results based on a culture of priorities built at maneuver, tactical, and strategic levels. The process proposed contributes to differentiate between the desired objectives-what we want to protect-from the more robust, feasible results: what we can protect and the price paid (eliminating sources of uncertainty for safe, efficient tactics and operations, and accepting the price to be paid for such certainty).

The role of the strategic level is to map a range of possible future outcomes and roughly estimate uncertainty triggers and, if possible, likelihoods (Table 1). In order to build these scenarios, particular attention should be paid to identify situations for which safety protocols may not work, scenarios for which fire services may not be resilient, or situations for which individual risks are protected instead of the common good. The strategic level should aim to provide resolution when safety, resiliency, and common good are possible with the available information. This level should also provide guidance to make tactical decisions when uncertainty arises. Finally, the maneuver level provides credibility and leadership.

The decision-making method could, theoretically, be implemented under any organizational framework (e.g., Australasian Inter-service Incident Management System, American Incident Command System), although it has to be adapted to the different pace of decision-making and long-term uncertain scenarios. Some interesting explorations in a similar direction have been done that focus on better understanding the long-term values to be preserved, the quantification of uncertainty, and the development of risk assessments tools (Thompson et al. 2016; O'Connor et al. 2017; Riley and Thompson 2017).

To apply this framework, the structure of decisionmaking should change from a detailed command and control structure that provides speed to operations, to a mission command structure (Department of Army 2003), that provides tactical flexibility in pursuing strategical objectives. To achieve it, tactical decisions should be made at the fire line. The tools, means, and knowledge to create certainty at different levels (i.e., maneuvers, tactics, and strategy) need to be systematized in order to empower the decision-making capacity at the fire line.

\section{Strategic objectives and principles}

The current firefighting trap and defensive strategies could be averted by empowering firefighters to adopt creative decision-making models that provide certainty, safety, and operational indicators. This requires reshaping the basic principles-firefighter safety, leadership, and resilience-and adapting them to take into account the actual global-change context of dynamic and complex environments.

Empowered strategic decision-making for wildfire management means that the information collected for making a decision must be structured according to a culture of priorities. To protect values at risk, uncertainty needs to be considered at the strategic level. This would allow the effective application of known procedures at tactical and maneuver levels. Defining strategic objectives based on universal organizational values can be of help in identifying the scenario of resolution (Table 2). In this approach, scenario choice helps organizations to clearly identify their responsibility.

The creative decision-making method proposed is based on four principles that help choose the resolution of a wildfire emergency. The four principles help to design a more creative decision-making process that empowers the fire line (Fig. 2). If scenarios are more certain, safety protocols and predictability have a higher probability of being successful tools:

\section{- Principle 1) Decision-making vision: a predictable} situation is a safe situation. Safety protocols and personal protective equipment are the main tools for safety in emergency management (Putnam 1995). When risks are predictable, the emergency system is robust, given that the teams follow the rules, routines, and procedures. However, when risks are not predictable and the scenario is uncertain, the teams cannot simply adapt to complex and rare situations by following procedures based on known errors and lessons learned. Common sense is also an ability required to avoid unnecessary and unmanageable risks that will only conclude in wasting resources while trying to succeed in impossible operations, endangering the crews, population, and future response capacity.

- Principle 2) Decision-making culture during the response phase: credibility to build trust and resiliency. Reducing uncertainty from a scenario and, as a consequence, increasing safety for firefighters and society requires being realistic in what can be achieved. Thus, decisions should be based in the certainty of gain and loss. The final result is somewhat known when the scenario is defined, and therefore the losses are expected. Communication with policy makers and society should be fluent, clear, and realistic about expectations in order to 
Table 2 Proposed uncertainty matrix. This tool helps identify different response options according to the analysis of uncertainty

\begin{tabular}{|c|c|c|c|}
\hline Objective & $\begin{array}{l}\text { Method used to achieve } \\
\text { objective }\end{array}$ & Weakness & Ways to build strength \\
\hline Maintain safety & Safety procedures & $\begin{array}{l}\text { Unpredictable changes of fire behavior when } \\
\text { safety that is based on standard operating } \\
\text { procedures fail. }\end{array}$ & $\begin{array}{l}\text { Identify known sources of unpredictable } \\
\text { situations when safety can be compromised } \\
\text { (e.g., possible plume collapse, downbursts). } \\
\text { Must assume the cost of choosing a } \\
\text { predictable scenario of resolution for } \\
\text { maneuver level over a scenario that reduces } \\
\text { known risks. }\end{array}$ \\
\hline $\begin{array}{l}\text { Maintain capacity } \\
\text { to respond } \\
\text { (organizational } \\
\text { resilience) }\end{array}$ & $\begin{array}{l}\text { Tight control of a large } \\
\text { number of resources }\end{array}$ & $\begin{array}{l}\text { Defense of all values at risk leads to no capacity } \\
\text { to respond to new threats. }\end{array}$ & $\begin{array}{l}\text { Identify when it is acceptable that the } \\
\text { opportunity cost of defending a value may } \\
\text { lead to losing the capacity to respond (e.g., } \\
\text { protecting one house and letting the fire } \\
\text { burn more wildland until it threatens five } \\
\text { more houses). } \\
\text { To maintain organizational resilience, the } \\
\text { strategic level should focus on opportunities } \\
\text { for the whole scenario, not only for the } \\
\text { maneuver level. The cost of both, what is } \\
\text { done and what cannot be done, must be } \\
\text { considered. } \\
\text { The tactical level then focuses on maximizing } \\
\text { organization resilience, allowing the } \\
\text { maneuver level to focus on protecting values } \\
\text { at risk. }\end{array}$ \\
\hline $\begin{array}{l}\text { Maintain initiative } \\
\text { and build trust } \\
\text { (leadership) }\end{array}$ & $\begin{array}{l}\text { Prioritize according to known } \\
\text { risk and defend values with } \\
\text { higher probabilities of } \\
\text { damage }\end{array}$ & $\begin{array}{l}\text { The decisions made by the firefighting services } \\
\text { impact the evolution of the scenario and lead to } \\
\text { new mid- and long-term threats and uncertain- } \\
\text { ties. While defending lives and assets under a } \\
\text { known, certain risk, firefighting services lose other } \\
\text { values from uncertain threats. }\end{array}$ & $\begin{array}{l}\text { Analyze and act to reduce possible final } \\
\text { damages. The strategic level maps future } \\
\text { landscapes by prioritizing the identification of } \\
\text { triggers of uncertainty that can cause more } \\
\text { damage. } \\
\text { The strategic decisions frame the decision- } \\
\text { making of the tactical level. } \\
\text { Agreement with society on values that will } \\
\text { survive, based on common good, and on } \\
\text { tomorrow's landscape. }\end{array}$ \\
\hline
\end{tabular}

build credibility (Weir et al. 2017). For this reason, some messages should be avoided (e.g., "we are doing our best to protect the community"). Instead, using messages that are accurate and genuine will enhance credibility on the decisions made by the emergency responders (e.g., "that will happen, and what we can do is avoid this and this from happening.").

- Principle 3) Values considered in the decision-making process: lead the "common good." Landscape values are diverse. These include ecological, social, economic, and safety values, among others. Common good is choosing a certain combinations of those values that have clear benefit for all of the population. Assuming that losses are unavoidable in any fire emergency, responders should select a final result, and use their resources strategically to minimize the loss of landscape and societal values. For instance, choosing to lose one building in a fire, if that allows protecting two. By taking into account common good, emergency responders generate certainty and credibility.

- Principle 4) Responsible decision-making: lead for tomorrow's landscapes. Decisions made during emergencies shape future landscapes and, therefore, future wildfire risks. Decision makers today are responsible for future systemic resilience and common good, which will affect future generations. It is necessary to include the future into the decision-making process.

An uncertainty matrix (Fig. 3) based in game theory gives different response options to the scenario and the events happening. The matrix has two main components, (1) what is known and unknown from the emergency response system perspective, and (2) what is known and unknown from the scenario. The matrix helps in addressing uncertainty in the strategy and tactics of a decision-making process that, in the meantime, can help to build resilience and credibility.

The matrix (Fig. 4) can be used to constantly assess any potential change during emergency to know in any moment the internal situation (where we are, what we are doing, and what is happening) and the external situation (what is happening and how it is changing). Firefighters should aim to always work and make decisions in known and predictable situations (Known Known). A Known Known situation is when decision makers are 
(1) All strategies are based on the safety of the crews.

(2) Safety is proportional to the certainty of the scenario.

Principle 1. Select from the potentia scenarios those that reduce the uncertainty in terms of predictability evolution.

Principle 2. Select from the potential scenarios those that enhance credibility while reducing uncertainty.

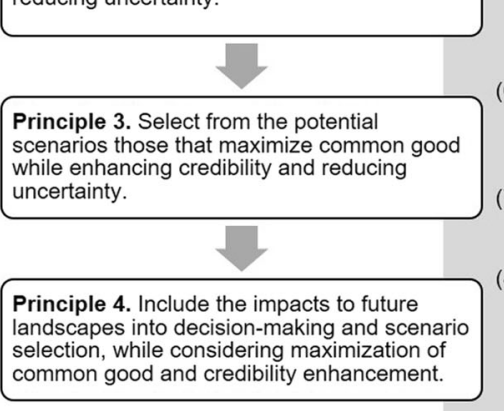

(3) Certainty of resolution is given when the working scenario is defined based on the minimal loss among the different possibilities.

(4) Measurable uncertainty becomes a risk, but uncertainty is transformed to certainty when results of an action are identified and accepted.

5) Results get predictable and safe. This is possible given the organizational resilience (knowing the work capacity of the emergency system and the threshold to avoid collapse).

(6) Organizational resilience is the first indicator of certainty (and safety) of a scenario. Credibility is then basic connection with society.

(7) Values should arise from the range of spatial and temporal impacts of the decisions taken.

8) The priority of values at risk: "lives, assets, and environment", is fundamental; however, it should be adapted to include organizational resilience as a principle. If the system is overwhelmed by the fire, the priority of values at-risk also collapses.

(9) Common good means that two lives are more valuable than one and two properties are more valuable than one. Thus, two crews cannot sacrifice to save one, but one can sacrifice to save two.

Fig. 2 Degrees of uncertainty and types of analysis. Rows 2 to 4 indicate what can be understood, identified, and foreseen. Row 5 indicates the type of analysis identified to be effective for each degree of uncertainty. Adapted from Courtney et al. (2000)

aware of the performance and availability of their teams and the logistics problems are under control. Also, the weather forecast is robust and fire is not extreme and behaves according to fuel models. Thus, there is no uncertainty in the wildfire. A Known Unknown situation is when decision makers are aware of the performance and availability of their teams and the logistics problems are under control. However the forecast (i.e., weather, fire behavior) is uncertain. For example, when a wind shift is forecasted at a predicted time, the conditions and impact of this wind shift on fire behavior are uncertain. Fire services follow the models, and it is certain that it will

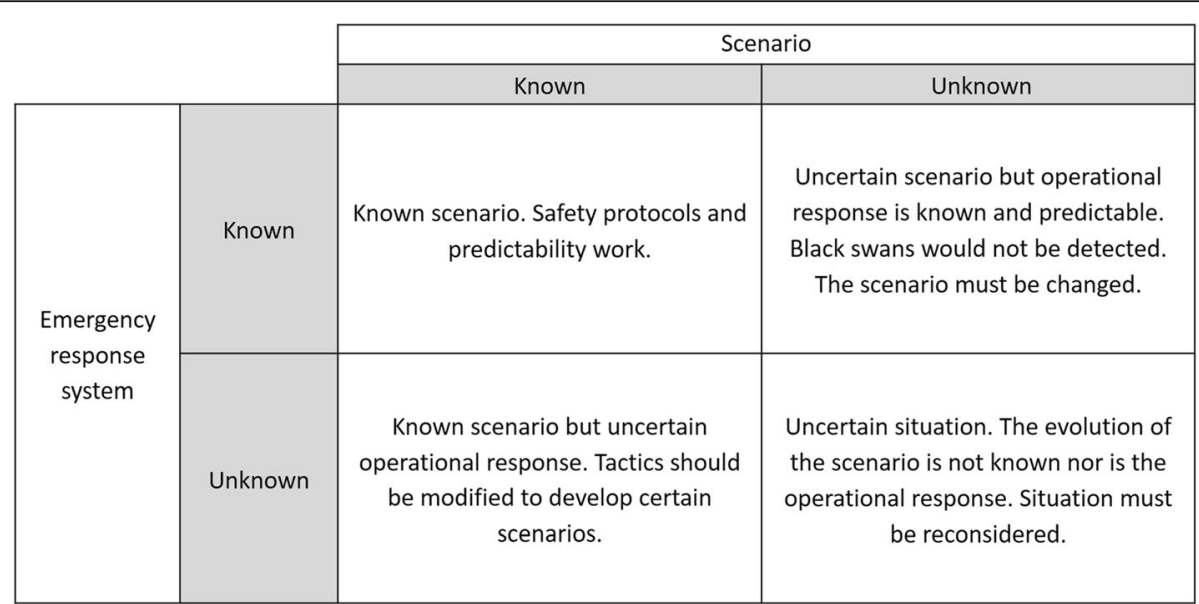

Fig. 3 Principles and guidelines that should be taken into account when choosing the resolution scenario based on the proposed creative decision-making 


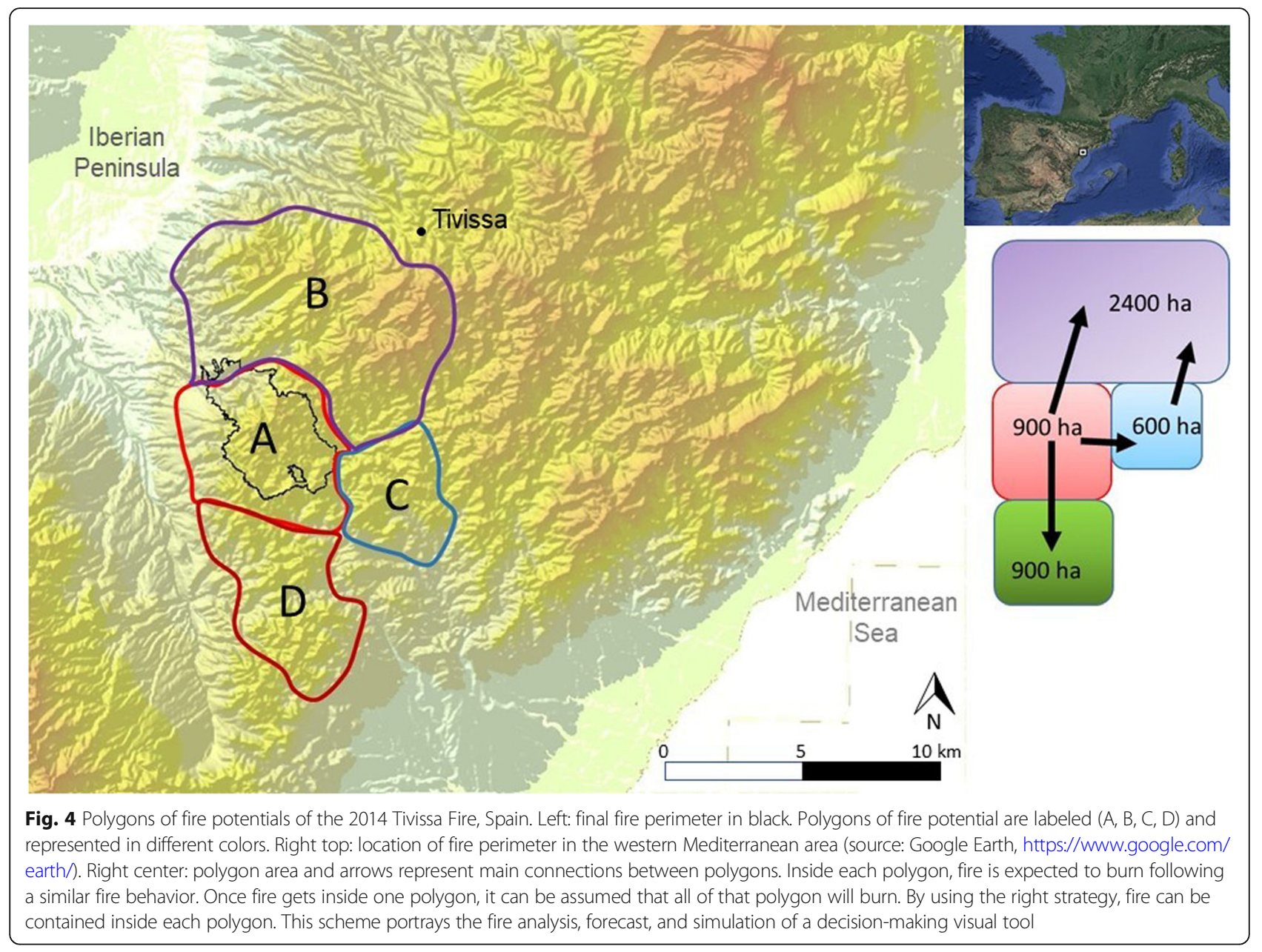

happen, but the conditions and the impact of the wind shift on the fire are yet uncertain. By integrating scientific knowledge into the decision-making process, unknown and unpredictable scenarios can be managed. Decision makers should aim to control those factors to transform the situation into a Known Known. An Unknown Known situation is when the performance of the teams and their capacities are uncertain. In this situation, the fire scenario and the weather is known, so decisions rely on experience. When expert knowledge is integrated, actions are based on experience but without scientific backup. Finally, an Unknown Unknown situation is when the performance of the teams, the scenario, the weather, and the fire behavior forecast are all uncertain. For instance, scenarios of extreme fire behavior for which nothing is certain, and unexpected situations can happen at any moment.

\section{Polygons of fire potential}

An innovative and already operational tool that helps identifying and managing uncertainty in Mediterranean Europe is the identification of polygons of fire potential.
The wildfire should be divided into polygons of fire potential that incorporate uncertainty to help define the scenario of resolution (final result). The polygons help provide an overview of the fire (to experts and nonexperts) of what can burn, what can be decided, and what will be saved and lost with every decision. The polygons eliminate uncertainty and provide a clear and certain picture. With this tool, decision makers are no longer doing "what we can," but "what we decided based on value and operational capacities."

A polygon of fire potential identifies spatial units for which fire behavior (i.e., high, medium, low) is expected to be homogeneous. Each polygon is characterized for a set of certain values (Fig. 4). Inside the polygon there are limited opportunities to deploy operational response constrained by a range of limitations (e.g., unstoppable expected fire behavior, limited road access, limited resources, unavailability of information for the right actor, place and time). Thus, the main operational opportunities are between polygons. The connectivity between polygons is then the window of opportunity to stop the wildfire and decide 
the final result. But, this connectivity is often dynamic and varies according to changes in fire scenarios (e.g., environmental conditions, success of the maneuvers and tactics).

Then, the classic formula of lives, properties, environment includes the no-collapse value, which implies selecting the final strategic outcome using a common good approach and including ecology and future landscape resilience in decision making. This strategic decision fixes the tactical decision and priority maneuvers to be made. Credibility is built between fire service and stakeholders. To demonstrate the implementation of the proposed methods, two examples of real wildfires for which creative decision making was applied are presented.

\section{Simple practical example: 2014 Tivissa Fire, 832 ha}

A lightning fire was detected on 14 June 2014 at 17:35 h in Tivissa, Tarragona, Spain. The fire was remote, in the middle of a young stand of Pinus halepensis Mill. regeneration after another fire in 1967. The forest was dense, 3000 to 8000 pines $\mathrm{ha}^{-1}$ between 4 and $7 \mathrm{~m}$ tall. The ecosystem was homogeneous and continuous for almost 12000 ha, identified as a problem for biodiversity and wildfire risk.
At the start of the fire event, the methodology presented here was used. Four polygons were identified representing the fire potential according to type of fire behavior based on terrain and fuel types (Fig. 4). Historical fires in the area, from years 1989 and 1967 (3285 ha and 11598 ha, respectively), were also used as references to define the polygons. The 2014 Tivissa Fire was suppressed within the first polygon (Fig. 4A). The fire behavior was analyzed considering the fluctuation of environmental conditions between night, with strong and dry northwest winds, and day, with moderate and more humid sea breeze (Table 3; Figs. 5, 6). The fire started in the afternoon, spreading out of control, and the fire behavior was already overwhelming the initial attack deployed by helitransported handcrews. In the evening, only $26 \%$ of the fire perimeter was contained. With the wind shift at midnight, the rate of spread was over $2 \mathrm{~km} \mathrm{~h}^{-1}$ and flames were between 5 and $10 \mathrm{~m}$. The infotoxicity during the initial hours (e.g., fire behavior, resources, wind conditions) overwhelmed decisionmakers and did not allow for focus on analysis of afternoon conditions after the wind shift. The initial attack was suspended and all crews were sent back into safe zones. A new strategy was needed.

Table 3 Summary of the decision-making analysis on a simple, practical example: the 2014 Tivissa Fire, Spain. Real situation assessment (A), and two different fire suppression strategies considered by the incident managers of the fire: the defensive strategy (B), and the creative decision-making strategy that was finally applied (C)

\begin{tabular}{|c|c|c|}
\hline $\mathrm{Sit}$ & & () \\
\hline $\begin{array}{l}\text { 4). Fire } \\
\text { to } \\
\text { S B is a } \\
\text { last } \\
\text { st. } \\
\text { uld } \\
\text { ntially } \\
\text { C } \\
\text { d }\end{array}$ & $\begin{array}{l}\text { maining fire. If polygon A cannot be attacked } \\
\text { rectly, the initial attack fails. The fire is then de- } \\
\text { ding where resources should go to work. } \\
\text { tere is no strategic plan, no tactical approach, } \\
\text { st operations to chase the flames threatening } \\
\text { sets at risk. } \\
\text { Since values at risk are in polygon D, the } \\
\text { cus is on polygons A to D. The operation can } \\
\text { icceed or fail depending on the speed of fire } \\
\text { read (Known Unknown; Fig. 3). Uncertainty } \\
\text { creases and does not allow focus on the }\end{array}$ & $\begin{array}{l}\text { le } \\
\text { fire service } \\
\text { the wind shift. } \\
B \text { is set as the } \\
\text { e. It is a good } \\
\text { e window } \\
\text { expected to } \\
\text { is is a Known } \\
\text { o Known } \\
\text { change if the } \\
\text { roken before }\end{array}$ \\
\hline
\end{tabular}

12000 ha region by half. Since the area is $\quad$ (5) Easy collapse of the system. habitat for eagle (Aquila fasciata Vieillot, 1822), an endangered species, opening the habitat and allowing a hunting ground for the eagle is a need to be considered.

(5) Must accept the risk of losing A and D. It's a Known Unknown situation at night, but if the fire does not get to $D$, it can then be controlled next morning. 


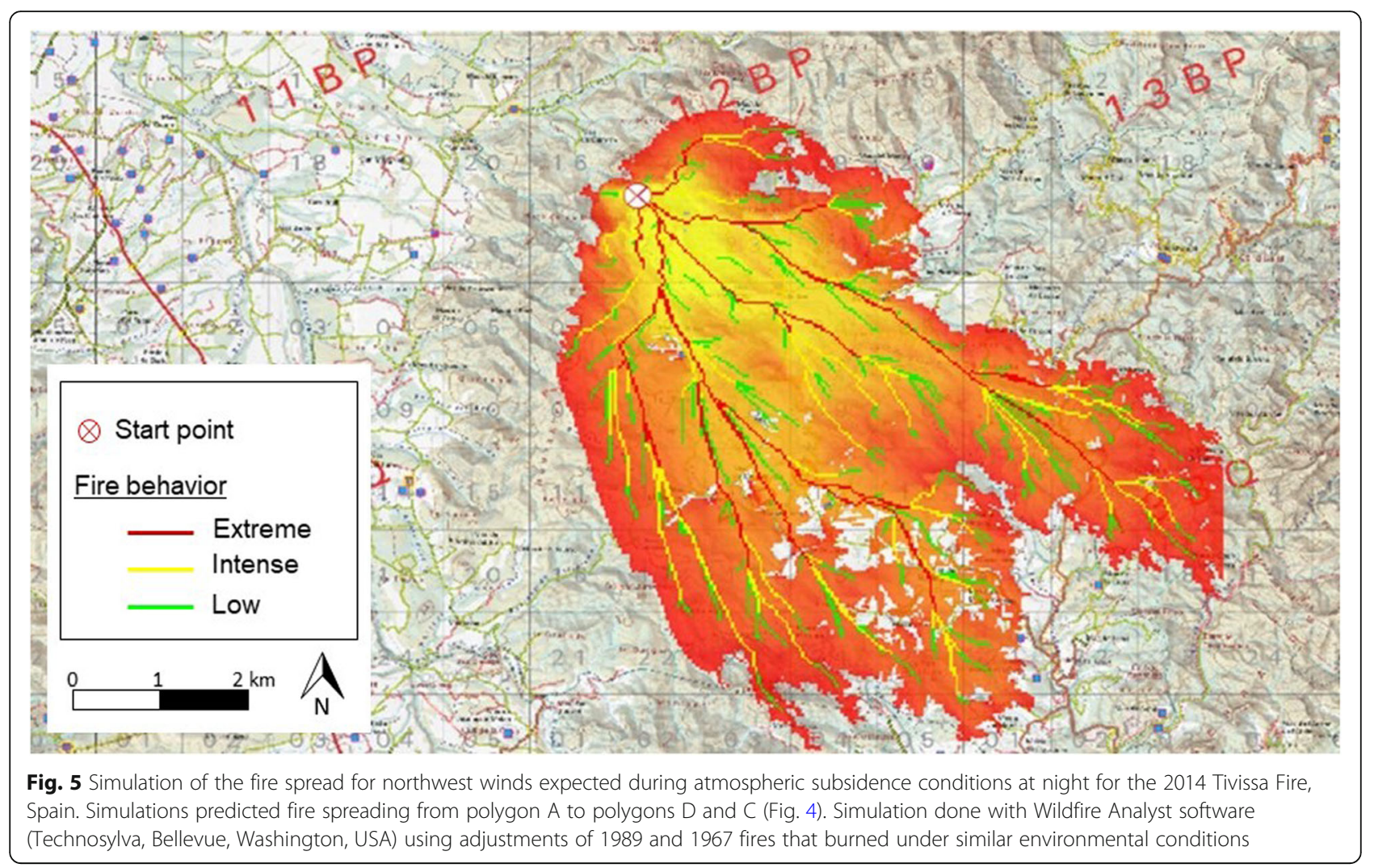

The opportunities and risks for operational deployment were analyzed using the uncertainty matrix (Fig. 3) and the analysis of polygon connectivity (Fig. 6). The result was that the fire service successfully managed to contain fire inside polygon A (Fig. 4). The 832 ha patch created a mosaic that was protecting 11000 ha of forest in two pieces. It increased the habitat of the eagle and created grassland with a good forest regeneration. The WUI is now protected from natural lightning fires that happen every year in those mountains. Almost 230 ha of the 832 ha were underburned and created a new habitat of open stand savanna ecosystem. Thus, three types of habitat were created by the fire. In addition, although 832 ha burned, a larger area of 4500 ha and the adjacent WUI were protected.

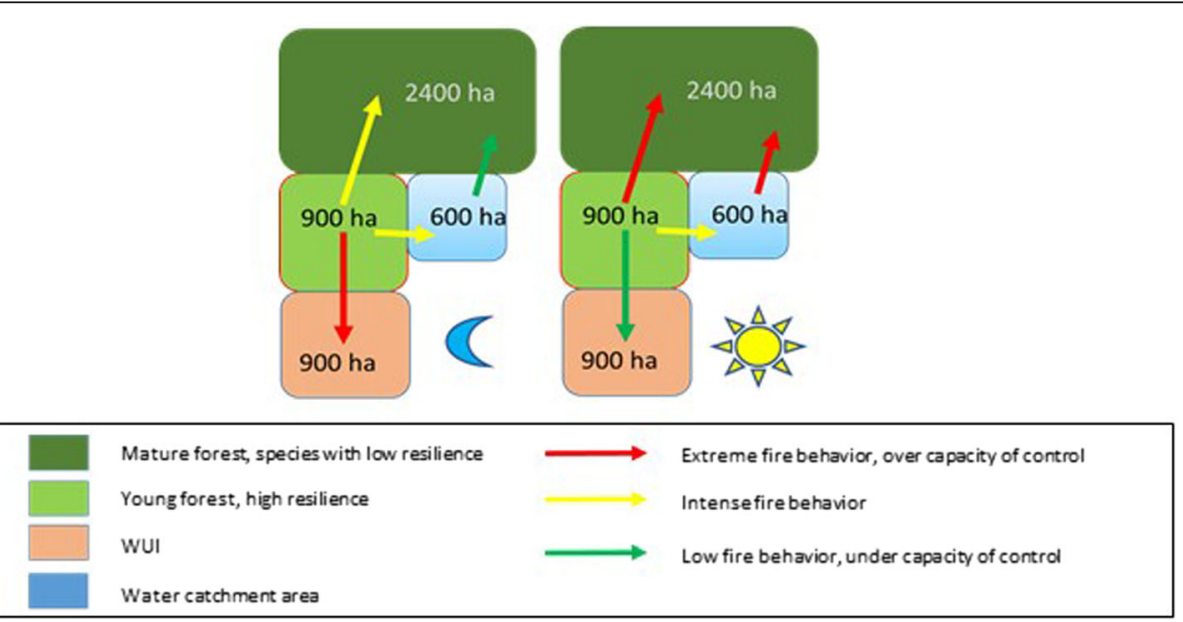

Fig. 6 Example of the graphic application of the creative decision-making method for night (left) and day (right) scenarios. Polygon colors indicate main values at risk within each area. Arrow direction indicates fire spread direction and color of the arrow indicates fire behavior: red indicates extreme fire behavior, yellow indicates intense fire behavior, and green indicates low fire behavior. This simplified scheme is a useful tool for discussing tactical and strategic decisions with different actors 
In conclusion, the 2014 Tivissa Fire example shows how creative decision-making helps build a strategy based on reinforcing the value of lives, property, and environment at the strategic, tactical, and maneuver levels. To build trust within agencies and between agencies and citizens, it is necessary to have clear and transparent communication. This is achieved by sharing and engaging all actors in the creative decision-making process proposed in this article. The outcome is a strategy shared with the citizens to build landscape resilience and preparation for future events.

\section{Complex practical example: 2015 Odena Fire, 1214 ha}

The 2015 Odena Fire was a wind-driven fire starting in a forest area (Pinus halepensis) regenerated after the 1986 fires. WUI and RUI (rural urban interface with farms) were scattered in the area (Table 4; Fig. 7). This area is on the edge of the continental-Mediterranean semihumid climate, and ecosystems are adapted to the dry conditions. The fire caused stress as Montserrat National Park was within the area of interest. The Park includes a high density of tourists and the whole area is near the metropolitan area of Barcelona (Fig. 7, polygon 13). The weather forecast indicated that western winds would dominate in the afternoon, and then south-southeast winds would prevail. The latter is a more calm and humid wind that improved weather conditions. Thus, there were two scenarios in a complex terrain surrounded by very sensitive values at risk (Fig. 8).

In the end, 1214 ha burned, considerably less than the 6000 ha that could have burned (Fig. 8). Four farms and one WUI area were affected. However, nine WUI areas

Table 4 Summary of the decision-making analysis on a complex, practical example: the 2015 Odena Fire, Spain. Real situation assessment (A), and two different fire suppression strategies considered by the incident managers of the fire: the defensive strategy (B), and the creative decision-making strategy that was finally implemented (C)

\begin{tabular}{|c|c|c|}
\hline (A) Situation assessment & $\begin{array}{l}\text { (B) Defensive strategy } \\
\text { (attack with uncertainty) }\end{array}$ & $\begin{array}{l}\text { (C) Creative strategy applied } \\
\text { (certain scenario) }\end{array}$ \\
\hline $\begin{array}{l}\text { Values at risk } \\
\text { (1) Complex scenario with pressure to avoid fire } \\
\text { burning the WUls and to avoid flames reaching } \\
\text { the national park (Fig. 8). } \\
\text { (2) While wind is blowing, this type of wind- } \\
\text { driven fire is really difficult to stop at its head. } \\
\text { Windows of opportunity need to be assessed in } \\
\text { order to get certainty to manage the wind } \\
\text { scenario. The fire was divided into two situations: }\end{array}$ & $\begin{array}{l}\text { (1) If efforts are concentrated on protecting the } \\
\text { national park and the WUI, then fire would hit } \\
\text { both as a head fire, and chances of losing the } \\
\text { WUI, RUI, and national park are high. There are } \\
\text { too many values at risk to defend, and fire can } \\
\text { easily grow. Realistically, there are two main } \\
\text { connections between polygons where the fire } \\
\text { cannot be stopped once it gets there before } \\
\text { the wind shift (red connections, Fig. 8a) } \\
\text { Focusing on them (Known Unknown) means }\end{array}$ & $\begin{array}{l}\text { (1) Look for the safe and certain scenario using } \\
\text { the uncertainty matrix (Fig. 3). For instance, the } \\
\text { fire service knows that it can succeed in } \\
\text { breaking connectivity between } 1 \text { and } 3.1 \text { and } 6 \\
\text { (north flank) at the beginning. If the fire is not } \\
\text { controlled then, it will unlikely be stopped after } \\
\text { the wind shift. The fire service also knows that } \\
\text { they can successfully protect the WUI and the } \\
\text { east side of the national park once the wind } \\
\text { shifts. Those are the certain tactics. }\end{array}$ \\
\hline
\end{tabular}
(2a) west winds would push a fast and intense fire working on uncertain resourcedemanding toward the WUI area around Montserrat National scenarios than would likely cause collapse. Park. (2b) late afternoon, the fire would shift following the north-northwest wind, it will drive away from the WUI and National Park, leaving a new and much wider fire head running into the RUls and the more sensitive forest ecosystem that could change to shrubland once burned.

(2) Initially, resources will be allocated to protect the WUI at polygons 4.1 and 5.2 but without stopping the fire, then WUI at 7, 8,9 and 18 . The protection of the national park would be required if fire hits polygons 7 and 8 (Fig. 8).

\section{Emergency management}

(3) Scenario 1: protect WUI and National Park but risking RUI and a fragile ecosystem (left flank polygons, Fig. 8).

(3) While protecting the WUIs and the national park, the fire will shift north and northwest,

bringing RUI and sensitive ecosystems into the equation.

(4) Scenario 2: protect RUI and fragile ecosystem and minimize the damage in WUI (protection and prevention measures applied before). The national park would burn: the area has a resilient ecosystem that would easily recover; nevertheless, it would create a visual impact jeopardizing tourism.

\section{Fire ecology management}

(5) The area affected by 1986 fires is a young pine forest (Pinus halepensis). Before, part of this land was covered by Pinus nigra Arnold and Quercus faginea Lam., but after those fires, more xerotinic species dominated the landscape.

(4) The defensive approach of chasing flames based on traditional value-at-risk approach would then drive the fire service to collapse. Once there, basic values of life and property would not be defended at all, anywhere.

(5) Under this scenario, the fire is a major incident that would only be solved due to weather improvement, after losing thousands of hectares. It's a classic situation that causes frustration for firefighters and distrust among the population of the country.
(2) The creative tactics proposed are to use windows of opportunity and accept the cost of them.

(3) Breaking the connection between polygon 1 and 3.1 (Fig. 8a) leads to major spread of head fire going to 4 . Flank connectivity to 5.2 can also be broken. This will leave a narrow and slower wind-driven fire.

(4) Focus on the left flank before the wind shift, as a way to avoid the possible head fire to polygon 6.1 and 6.2 .

(5) If the fire is kept narrow, it will spread with much less energy and can develop less convection. Power of fire (Rothermel 1991) stays lower until the wind shift, and allows the fire service to be ready to stop the connection from $4 \mathrm{~s}$ to $8 \mathrm{~s}$, national park and WUI.

(6) Once the wind shifts, connections to polygon 6 will be active (Fig. 8b). The narrower, the better. What happened is that, the connections to polygon 6 were only two narrow strips under control before connection to 6 was established. 


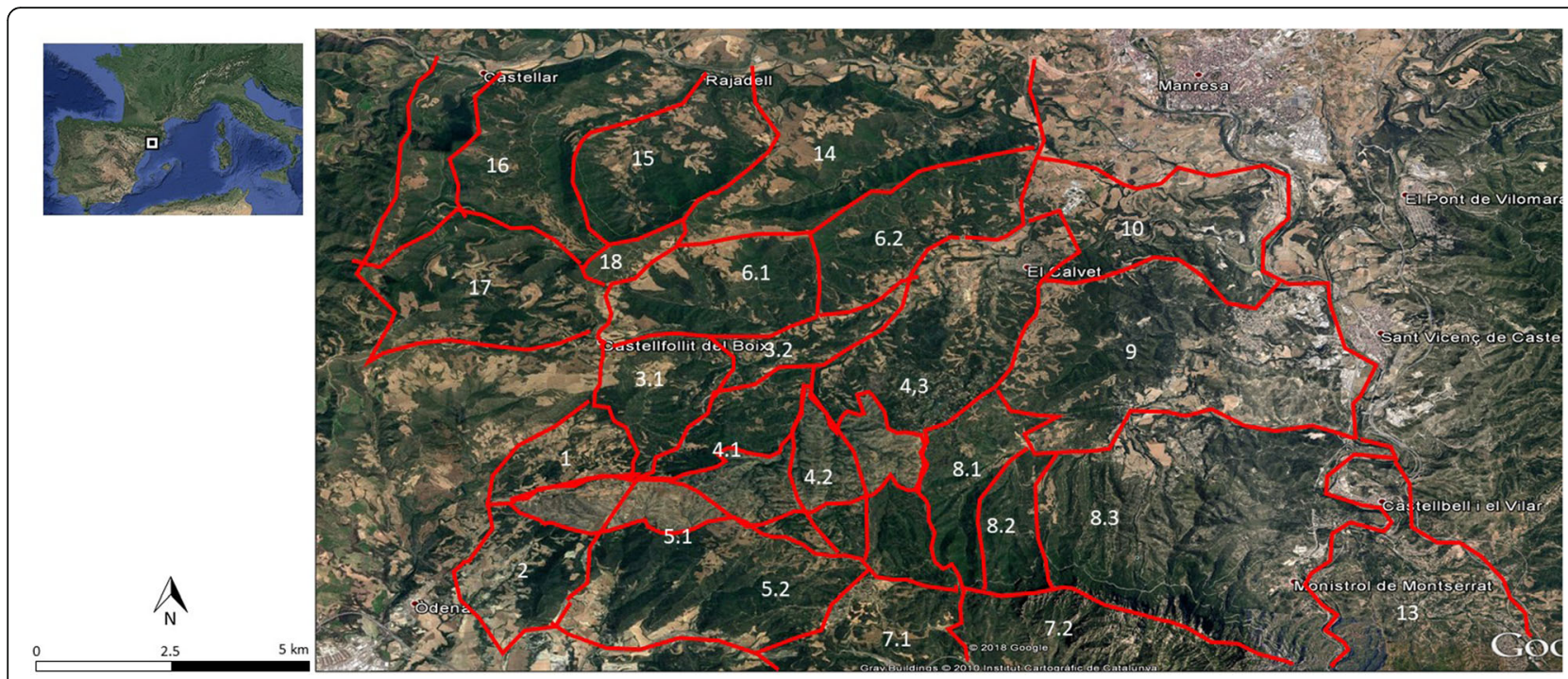

Fig. 7 Segmentation of the area of interest of the 2015 Odena Fire, Spain, into polygons of fire potential, as part of the creative decision-making process. Numbers indicate polygon labeling. Fire started at polygon 1. Some polygons have been split into smaller sections to identify tactical objectives (i.e., 4, 5, 6, 7, and 8). Left: location of fire perimeter in the western Mediterranean area. Source: Google Earth (https://www.google.com/earth/)

did not burn. These southern-wind-driven fires, such as the 2015 Odena Fire, have devastated this Catalan area several times in recent years (e.g., 1994, 1998, 2003, 2005; Brotons et al. 2013). But now a long fire scar works as a fuel break against wildfires driven by southern winds, protecting against megafires that could affect the area under the current climate change scenario (Alcasena et al. 2019). Megafires are relatively new in Mediterranean Europe, but their occurrence is increasing with climate change (Cardil et al. 2015; Duane and Brotons 2018). Besides reducing risk, the fire scar breaks the monospecific landscape continuity and creates habitat. The biodiversity of the region has improved, including an increase of the number of big mammals. The fragile, semi-humid ecosystem remained unburned, and the littoral forest that burned is quickly recovering. Most of the RUI was protected and the economy of the area is currently growing.

The methods presented in this case study were used to discuss the emergency management strategy deployed within the local communities, as well as the positive and negative impacts of the fire. The polygons of fire potential tool was very helpful: first, in helping to understand how uncertainty is managed; second, in identifying the limitations of the fire suppression system; third, in raising risk awareness among residents; and fourth, in encouraging citizens to manage their own risk and prepare for future fires.

\section{Conclusions}

Uncertainty in emergency management is forcing defensive actions against known risks. Focusing on traditional values at risk has two main consequences in Mediterranean Europe: firstly, the collapse of fire services, and secondly, the loss of landscape and values that could, in fact, be saved. Following a creative methodology to define the resolution of a wildfire event, instead of focusing on protecting values at risk, allows for a systematic way to manage uncertainty through decision-making. Of course, lives and property must be protected, but the focus should not only be on them. Avoiding collapse of fire services is necessary to ensure life and property protection and to ensure that decisions made will maximize the common good. Improving resilience of fragile ecosystems and biodiversity should be included in the values to be considered during emergency management. Using the creative decision-making approach proposed, fire services can avoid collapse and include fire ecology as a value to create resilient landscapes of the future. As seen in the examples provided, common good allows including fire ecology values as strategic decision-making values and, most important, allows using emergency management to create future landscape mosaics and protect rural economy.

By adopting this approach, fire emergencies will turn a rather negative feeling of losing the past and ruining the future to a positive one of helping to build landscape and societal resilience for future wildfires.

Fighting against extreme wildfires means addressing a socio-ecological hazard with mid- and long-term impacts. A lesson learned is that using this methodology requires the involvement of people, from firefighters to communities. Often, citizens are informed but not involved, and this creates information noise. 


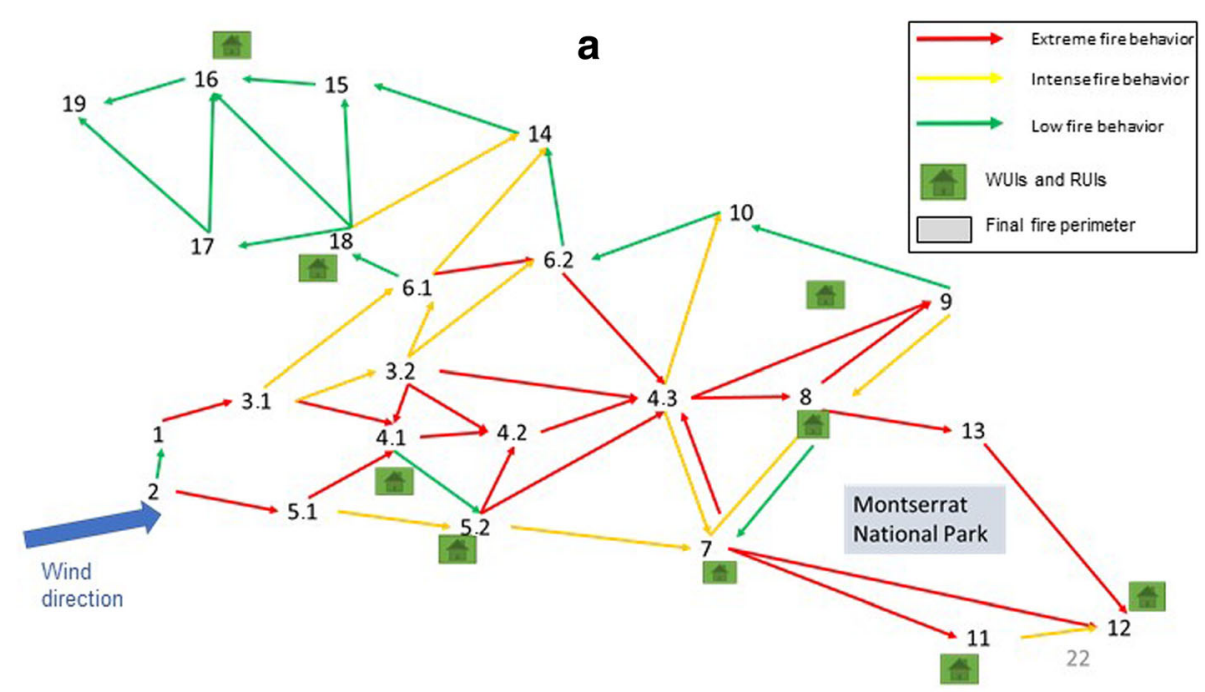

b

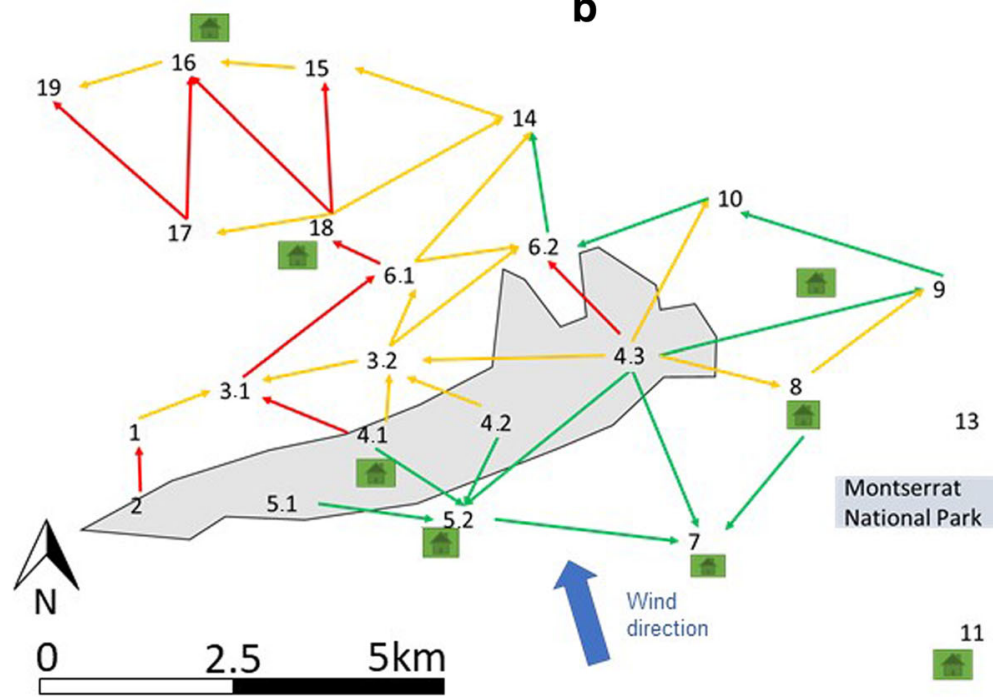

13

23

Fig. 8 Main connections between polygons defined in Fig. 7 under two wind conditions expected on the 2015 Odena Fire, Spain. (a) given west wind conditions at the start of the fire. (b) given wind shift to south-southeast conditions. Complexity of operational opportunities decreases with color (red, yellow, green). This schematic helps to keep focus on the information needed to make decisions by reducing noise from maps and simulations

In a time when information is readily available to everyone, it is a good option to involve society in the emergency decisions that are currently being made by a closed team that is responding to the emergency. The proposed methods can have profound implications to manage uncertainty in the information era.

\section{Acknowledgements}

We thank the firefighters from the Catalan Fire and Rescue Service that contributed to conceiving, developing, and implementing this methodology. Thank you to the firefighters, managers, and practitioners from other Spanish regions, Aix-en-Provence, Aude, Corsica, Sardinia, and Northumberland who have contributed valuable discussions during the creation of this methodology and, in particular, those who have implemented the methodology while fighting wildfires. The authors wish to thank Professor J. Hearne (RMIT University) for his suggestions, and one anonymous reviewer for helpful comments. We thank the Pau Costa Foundation community and their staff team for making the publication possible and for their sharing of operational knowledge.

\section{Authors' contributions}

$M C$ and MMiralles contributed to analyzing and synthesizing the contents of the document, NPG contributed to synthesizing and preparing the contents. EA, AL, EN, XC, JV, JPallas, JH, MMonturiol, JC, JPages, and CG contributed to providing personal experiences, collecting data, and preparing the methodology described in the document. All authors read and approved the final manuscript.

\section{Funding}

Not applicable.

\section{Availability of data and materials} Not applicable. 


\section{Ethics approval and consent to participate}

Not applicable.

\section{Consent for publication}

Not applicable.

\section{Competing interests}

The authors declare that they have no competing interests.

Received: 30 November 2018 Accepted: 26 June 2019

Published online: 20 August 2019

\section{References}

2009 Victorian Bushfires Royal Commission. 2010. 2009 Victorian Bushfires Royal Commission: final report. Melbourne: Government Printer for the State of Victoria http://royalcommission.vic.gov.au/Commission-Reports/Final-Report. html.

Alcasena, F.J., A.A. Ager, J.D. Bailey, N. Pineda, and C. Vega-García. 2019. Towards a comprehensive wildfire management strategy for Mediterranean areas: framework development and implementation in Catalonia, Spain. Journal of Environmental Management 231: 303-320 https://doi.org/10.1016/j.jenvman. 2018.10.027.

Bishop, M. 2004. Essential economics: an A to Z guide. New York: Bloomberg Press. Brotons, L., N. Aquilue, M. de Cáceres, M.J. Fortin, and A. Fall. 2013. How fire history, fire suppression practices and climate change affect wildfire regimes in Mediterranean landscapes. PLoS ONE 8 (5): e62392 https://doi.org/10.1371/ journal.pone.0062392.

BRP [Blue Ribbon Panel]. 2008. The Blue Ribbon Panel report on wildland urban interface fire. Washington, D.C.: International Code Council.

Butler, C.P. 1974. The urban/wildland fire interface. Proceedings of Western States Section Combustion Institute Papers 74 (15): 1-17.

Caballero, D., I. Beltrán, and A. Velasco. 2007. Forest fires and wildland-urban interface in Spain: types and risk distribution. Proceedings of the $\mathrm{N}$ International Wildfire Conference T5: 1-14.

Calkin, D.E., J.D. Cohen, M.A. Finney, and M.P. Thompson. 2014. How risk management can prevent future wildfire disasters in the wildland-urban interface. Proceedings of the National Academy of Sciences of the United States of America 111 (2): 746-751 https://doi.org/10.1073/pnas.1315088111.

Cardil, A., C.S. Eastaugh, and D.M. Molina. 2015. Extreme temperature conditions and wildland fires in Spain. Theoretical and Applied Climatology 122 (1-2): 219-228 https://doi.org/10.1007/s00704-014-1295-8.

Cardil, A., and D.M. Molina. 2015. Factors causing victims of wildland fires in Spain (1980-2010). Human and Ecological Risk Assessment: An International Journal 21 (1): 67-80 https://doi.org/10.1080/10807039.2013.871995.

Castellnou, M., A. Larrañaga, M. Miralles, and D.M. Molina. 2010. Wildfire scenarios: learning from experience. In Towards integrated fire management-outcomes of the European Project Fire Paradox. Research Report No. 23, ed. J.S. Silva, F. Rego, P. Fernandes, and E. Rigolot, 121-131. Joensuu: European Forest Institute.

Castellnou, M., J. Pagès, M. Miralles, and M. Piqué. 2009. Tipificación de los incendios forestales en Cataluña. Elaboración del mapa de incendios de diseño como herramienta para la gestión forestal. In Actas del 50 Congreso Forestal Español, 21-25 September 2009, Ávila, Spain. Sociedad Española de Ciencias Forestales y la Junta de Castilla y León [In Spanish.] https://www. recercat.cat/bitstream/handle/2072/281988/2009_Castellnou_CongrAvila. pdf? sequence $=1$.

Catalan Fire and Rescue Service. 2013a. Lo Forestalillo, número 155. Especial incendis en interfase urbana-forestal, 3-6. 2012 Jonquera Fire official report. https://bombersdotblogdotgencatdotcat.files.wordpress.com/2016/02/ forestalillo_155_cat.pdf Accessed 31 Mar 2019. [In Spanish.].

Catalan Fire and Rescue Service. 2013b. Lo Forestalillo, número 157. Campanya discontinua i amb inestabilitat, 8-14. 2013 Vallirana Fire official report. https:// bombersdotblogdotgencatdotcat.files.wordpress.com/2016/02/forestalillo15 7_cat.pdf Accessed 31 Mar 2019. [In Spanish.].

Chergui, B., S. Fahd, X. Santos, and J.G. Pausas. 2018. Socioeconomic factors drive fire-regime variability in the Mediterranean Basin. Ecosystems 21: 619-628 https://doi.org/10.1007/s10021-017-0172-6.

Collins, R.D., R. de Neufville, J. Claro, T. Oliveira, and A.B. Pacheco. 2013. Forest fire management to avoid unintended consequences: a case study of Portugal using system dynamics. Journal of Environmental Management 130: 1-9 https://doi.org/10.1016/j.jenvman.2013.08.033.
Costa, P., A. Larrañaga, M. Castellnou, M. Miralles, and D. Kraus. 2011. Prevention of large wildfires using the fire types concept. Tivissa: Pau Costa Foundation. https://issuu.com/paucostafoundation/docs/guia_paradox_eng_compr.

Courtney, H.G., J. Kirkland, and S.P. Viguerie. 2000. Strategy under uncertainty. McKinsey Quarterly. https:/www.mckinsey.com/business-functions/strategy-andcorporate-finance/our-insights/strategy-under-uncertainty Accessed 4 Jun 2019.

CTI [Comissão Técnica Independente]. 2017. Relatório. Análise e apuramento dos factos relativos aos incêndios que ocorreram em Pedrógão Grande, Castanheira de Pera, Ansião, Alvaiázere, Figueiró dos Vinhos, Arganil, Góis, Penela, Pampilhosa da Serra, Oleiros e Sertã, entre 17 e 24 de junho de 2017. Lisboa: Assembleia da República [In Spanish.]. (https://www.esquerda.net/sites/ default/files/relatoriocti12out2017.pdf).

CTI [Comissão Técnica Independente]. 2018. Relatório Final. Avaliação dos incêndios ocorridos entre 14 e 16 de outubro de 2017 em Portugal Continental. Edited by J. Guerreiro, C. Fonseca, A. Salgueiro, P. Fernandes, E. Lopez Iglésias, R. de Neufville, F. Mateus, M. Castellnou, J.S. Silva, J.M. Moura, F. Castro Rego, and D.N. Caldeira, coordinators. Lisboa: Assembleia da República. [In Spanish.]

Department of the Army. 2003. Mission command: command and control of army forces. Field manual no, 6-0. Washington, D.C.: Headquarters, Department of the Army.

Desmond, M. 2011. Making firefighters deployable. Qualitative Sociology 34: 5977 https://doi.org/10.1007/s11133-010-9176-7.

Diakakis, M., G. Xanthopoulos, and L. Gregos. 2016. Analysis of forest fire fatalities in Greece: 1977-2013. International Journal of Wildland Fire 25: 797-809 https://doi.org/10.1071/WF15198.

Duane, A., and L. Brotons. 2018. Synoptic weather conditions and changing fire regimes in a Mediterranean environment. Agricultural and Forest Meteorology 253-254: 190-202 https://doi.org/10.1016/j.agrformet.2018.02.014.

Lahaye, S., T. Curt, T. Fréjaville, J. Sharples, L. Paradis, and C. Hély. 2018. What are the drivers of dangerous fires in Mediterranean France? International Journal of Wildland Fire 27: 155-163 https://doi.org/10.1071/WF17087.

Miralles, M., D. Kraus, D.M. Molina, C. Loureiro, G. Delogu, N. Ribet, and O. Vilalta. 2010. Improving suppression fire capacity. In Towards integrated fire management-outcomes of the European Project Fire Paradox. Research Report 23, ed. J.S. Silva, F. Rego, P. Fernandes, and E. Rigolot, 189-201. Joensuu: European Forest Institute.

Modugno, S., H. Balzter, B. Cole, and P. Borrelli. 2016. Mapping regional patterns of large forest fires in wildland-urban interface areas in Europe. Journal of Environmental Management 172: 112-126 https://doi.org/10.1016/j.jenvman. 2016.02.013.

Molina-Terrén, D.M., G. Xanthopoulos, M. Diakakis, L. Ribeiro, D. Caballero, G.M. Delogu, D.X. Viegas, C.A. Silva, and A. Cardil. 2019. Analysis of forest fire fatalities in southern Europe: Spain, Portugal, Greece and Sardinia (Italy). International Journal of Wildland Fire 28: 85-98 https://doi.org/10.1071/ WF18004.

Nasiatka, P. 2003. Southern California firestorm 2003. Report for the Wildland Fire Lessons Learned Center. Parker, Colorado, USA: Missions-Centered Solutions, Inc:; and Washburn, Wisconsin, USA: Guidance Group, Inc.

O'Connor, C.D., D.E. Calkin, and M.P. Thompson. 2017. An empirical machine learning method for predicting potential fire control locations for pre-fire planning and operational fire management. International Journal of Wildland Fire 26: 587-597 https://doi.org/10.1071/WF16135.

Palaiologou, P., A.A. Ager, M. Nielsen-Pincus, C.R. Evers, and K. Kalabokidis. 2018. Using transboundary wildfire exposure assessments to improve fire management programs: a case study in Greece. International Journal of Wildland Fire 27: 501-513 https://doi.org/10.1071/WF17119.

Pausas, J.G., and S. Fernández-Muñoz. 2011. Fire regime changes in the western Mediterranean Basin: from fuel-limited to drought-driven fire regime. Climatic Change 110: 215-226 https://doi.org/10.1007/s10584-011-0060-6.

Putnam, T. 1995. The collapse of decision making and organizational structure on Storm King Mountain. Missoula: USDA Forest Service, Technology and Development Center.

Riley, K.L., and M.P. Thompson. 2017. An uncertainty analysis of wildfire modeling. In Uncertainty in natural hazards: modeling and decision support, ed. K.L. Riley, M.P. Thompson, and P. Webley, 191-213. New York: Wiley and American Geophysical Union Books https://doi.org/10.1002/9781119028116.ch13.

Rothermel, R.C. 1991. Predicting behavior and size of crown fires in the northern Rocky Mountains. USDA Forest Service Research Paper INT-438. Ogden: USDA Forest Service Intermountain Research Station https://doi.org/10.2737/ INT-RP-438. 
San-Miguel-Ayanz, J., T. Durrant, R. Boca, G. Libertà, A. Branco, D. de Rigo, D. Ferrari, P. Maianti, T. Artés Vivancos, H. Costa, F. Lana, P. Löffler, D. Nuiiten, A. C. Ahlgren, and T. Leray. 2018. Forest fires in Europe, Middle East and North Africa 2017. JRC technical reports. Ispra, Italy: Joint Research Centre. https://doi. org/10.2760/663443.

San-Miguel-Ayanz, J., J.M. Moreno, and A. Camia. 2013. Analysis of large fires in European Mediterranean landscapes: lessons learned and perspectives. Forest Ecology and Management 249: 11-22 https://doi.org/10.1016/j.foreco.2012.10. 050.

Shannon, C.E. 1948. A mathematical theory of communication. The Bell System Technical Journal 27: 623-656 https://doi.org/10.1002/j.1538-7305.1948. tb00917.x.

Silva, J.S., F. Rego, P. Fernandes, and E. Rigolot, eds. 2010. Towards integrated fire management-outcomes of the European Project Fire Paradox. Research Report 23. Joensuu: European Forest Institute https://www.ucm.es/data/cont/ docs/530-2013-10-15-efi_rr23.pdf.

Taleb, N.N. 2007. The black swan: the impact of the highly improbable. New York: Random House.

Tedim, F., V. Leone, and G. Xanthopoulos. 2015. Wildfire risk management in Europe: the challenge of seeing the "forest" and not just the "trees." In: Proceedings of the 13th International Wildland Fire Safety Summit \& 4th Human Dimensions of Wildland Fire Conference, 20-24 April 2015, Boise, Idaho, USA, 213-238. Missoula: International Association of Wildland Fire.

Thompson, M.P., P. Bowden, A. Brough, J.H. Scott, J. Gilbertson-Day, A. Taylor, J. Anderson, and J.R. Haas. 2016. Application of wildfire risk assessment results to wildfire response planning in the southern Sierra Nevada, California, USA. Forests 7 (3): 64 https://doi.org/10.3390/f7030064.

Vega-Garcia, C., and E. Chuvieco. 2006. Applying local measures of spatial heterogeneity to Landsat-TM images for predicting wildfire occurrence in Mediterranean landscapes. Landscape Ecology 21: 595-605 https://doi.org/10. 1007/s10980-005-4119-5.

Wei, Y., M.P. Thompson, J. Haas, G.K. Dillon, and C.D. O'Connor. 2018. Spatial optimization of operationally relevant large fire confine and point protection strategies: model development and test cases. Canadian Journal of Forest Research 48 (5): 480-493 https://doi.org/10.1139/cjfr-2017-0271.

Weir, J.K., T. Neale, and L. Clarke. 2017. Science is critical but it's not everything: our findings. In Research Proceedings from the Bushfire and Natural Hazards CRC \& AFAC Conference, ed. M. Rumsewicz. Melbourne: Bushfire and Natural Hazards CRC https://www.bnhcrc.com.au/publications/biblio/bnh-3884.

\section{Publisher's Note}

Springer Nature remains neutral with regard to jurisdictional claims in published maps and institutional affiliations.

\section{Submit your manuscript to a SpringerOpen ${ }^{\circ}$ journal and benefit from:}

- Convenient online submission

- Rigorous peer review

- Open access: articles freely available online

- High visibility within the field

- Retaining the copyright to your article

Submit your next manuscript at $\boldsymbol{\nabla}$ springeropen.com 